\title{
LEAD POISONING IN INFANCY
}

\author{
BY \\ NORMAN S. CLARK \\ From the Department of Child Health, University of Aberdeen, and the Royal Aberdeen Hospital \\ for Sick Children
}

(Received for Publication December 1, 1949)

Lead poisoning in infancy and childhood is a well-recognized and apparently common condition in America. In Holt's 'Diseases of Infancy and Childhood' (1940) it is stated that ' lead poisoning is one of the common and most serious forms of intoxication recognized in childhood.' Byers and Lord (1943) reviewing the records of the Children's Hospital, Boston, found 128 cases of this condition during a ten year period. During the last 15 years a large number of papers on this subject have appeared in the American journals, many of them reporting a series of cases. In Great Britain, on the other hand, lead poisoning appears to be comparatively rare, or at least rarely recognized, in the early years of life, if the infrequency of published reports may be taken as a sound guide. Gordon and Whitehead (1949) have recently reported one case in an infant aged 6 months, Findlay (1935) reported one case in an infant of 3 months, and Rodgers, Peck, and Jupe (1934) one case in a child aged 2 years. The Index Medicus contains no record of any other papers on this subject in the British literature during the past 15 years.

The following report of a case of lead encephalopathy in a young infant may therefore be of some interest, and serve to draw attention to the diagnosis of a condition which may well be missed unless the possibility of its occurrence is constantly borne in mind.

\section{Case Report}

A boy aged 4 months was admitted to the Royal Aberdeen Hospital for Sick Children on July 19, 1947, on account of convulsions. He had been breast fed and had always appeared very well until two weeks before admission when his mother decided to discontinue breast feeding and changed his feeds to a full cream dried milk. From this time he became listless and began to vomit occasionally after and during feeds. He had no bowel upset and did not appear to have any abdominal pain. On the morning of admission he had a right-sided convulsion with muscular twitching persisting for half an hour, succeeded by temporary paralysis of the right arm and leg.

The infant was the first child of healthy parents and was born prematurely after a normal labour, his birth weight being $5 \mathrm{lb}$. Neither parent had complained of any symptoms suggestive of lead poisoning.

When examined on admission be was seen to be a pale infant in good general condition. The fontanelle was tense and there was a right facial paresis. No other abnormality was perceived.

During the first two days the facial paresis cleared up but convulsions recurred intermittently in spite of repeated large doses of chloral. For long periods there was muscular twitching involving at times the whole body and at times only the left side. After this the fits ceased spontaneously and did not recur, except for one brief, right-sided fit on the eighth day after admission. He took feeds well, did not vomit, and remained in good general condition.

Investigations. Routine urine examination was negative. Lumbar puncture on admission produced clear cerebrospinal fluid under normal tension: the fluid showed no increase in cells and the Wassermann reaction was negative but the protein was $80 \mathrm{mg}$. \%. Two weeks later the protein was $60 \mathrm{mg} . \%$, but the cerebrospinal fluid was otherwise normal.

\section{BLOOd Picture}

Red blood cells, 3,780,000 per c.mm.

Haemoglobin, $62^{\%}$ (Haldane).

Colour index, 0.82.

Reticulocytes, $5 \cdot 5 \%$

White blood cells, 8,200 per c.mm. (Polymorphs $25 \%$, eosinophils $1 \%$, basophils $1 \%$, lymphocytes $58 \%$, monocytes $13 \%$, myelocytes $1 \%$, Türk cells $1 \%$.)

A few of the red cells were normal; the rest were severely microcytic and hypochromic. There was no punctate basophilia.

Skiagrams (Fig. 1) showed dense marginal bands at the metaphyses of all the long bones and also at the anterior ends of the ribs.

The changes in the long bones in conjunction with the convulsions, the raised protein in the cerebrospinal fluid, and the hypochromic anaemia were strongly suggestive of lead poisoning but the history at first gave no hint of any possible source of lead. Neither parent had suffered from any symptoms suggestive of plumbism, the child had been wholly breast fed until the onset of symptoms, no nipple shields had been used nor had any medicaments been applied to the mother's nipples. The child's age ruled out the possibility of any prolonged period of sucking painted articles. Eventually the 


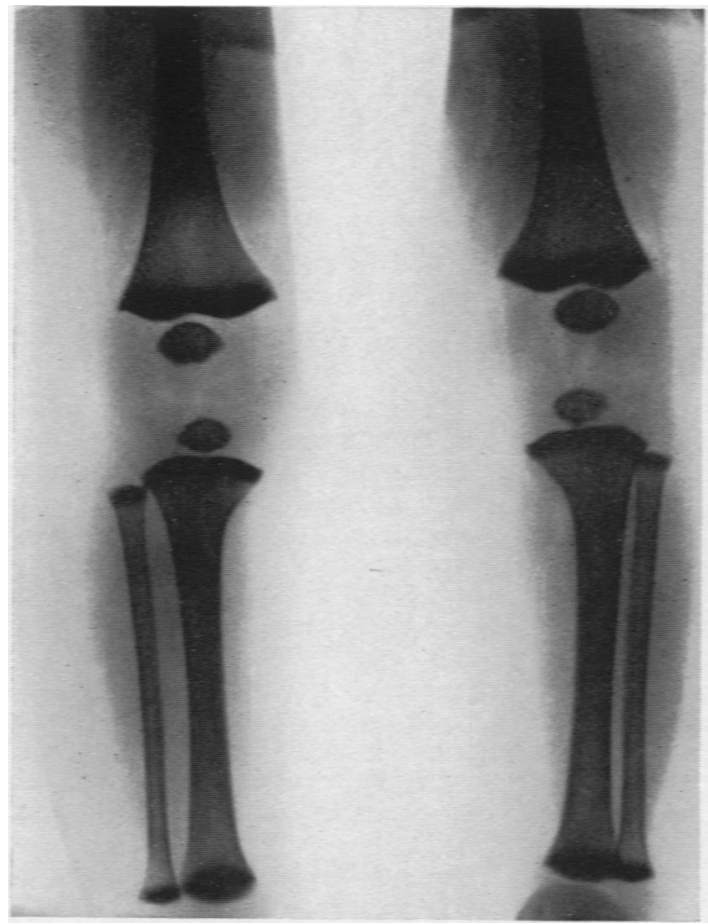

Fig. 1.-Dense bands at the metaphyseal borders on August 4, 1947.

mother volunteered that he had always been a very thirsty baby and since the age of 1 or 2 weeks had drunk about a teacupful of water daily in addition to his feeds.

Examination of specimens of tap water from the infant's home gave the following results:

Morning (first run off), 2.0 parts per 100,000.

After five minutes running, 1.4 parts per 100,000 .

Maximum safe limit, 0.05 parts per 100.000 (Suckling, 1943).

On further inquiry it was found that about one year previously new lead pipes had been installed in the house (a gardener's cottage on an estate in Aberdeenshire).

By the time the diagnosis was established the acute symptoms had subsided and no treatment was considered necessary other than the administration of vitamin $D$ in an attempt to hasten the deposition of lead in the bones. The infant was allowed to return home after the lead pipes had been replaced by asbestos piping and was seen again as an out-patient on December 11, 1947, when he was keen, healthy and making normal progress for his age. Skiagrams of the long bones (Fig. 2) showed double dense lines in the metaphyseal regions, one at the original site, now left behind in the shafts of the bones as a result of growth, and one at the metaphyseal borders. In view of this finding the possibility of further absorption of lead was considered but tests of the water supply showed it to be free from lead.

The baby remained under observation until June, 1949. During this period his general progress has been very satisfactory apart from some delay in his speech which is, perhaps, slightly behind the average for a child of his age. Skiagrams at intervals have shown the continued presence of double metaphyseal lines of slowly decreasing density: the second line has remained at the margin of the metaphysis and the distance between the lines is accordingly increasing with growth.

\section{Discussion}

Source of Lead. The many and varied sources of lead poisoning in nursing infants have been well reviewed in the recent paper by Gordon and Whitehead (1949). In their full list of references, however, there is no mention of a case attributable to lead in the family water supply. I also have been unable to find any reference to such a condition in a breast fed infant. While the determining factor in producing acute symptoms in the present case was probably the change from breast to bottle feeding two weeks before admission, with consequent increase in the lead intake, it is certain from the width and density of the metaphyseal lines and also from the fact that the first symptoms appeared at the time of weaning that absorption of lead had been going on for considerably longer than two weeks. Before this, of course, the infant had been drinking a considerable quantity of water, but it is

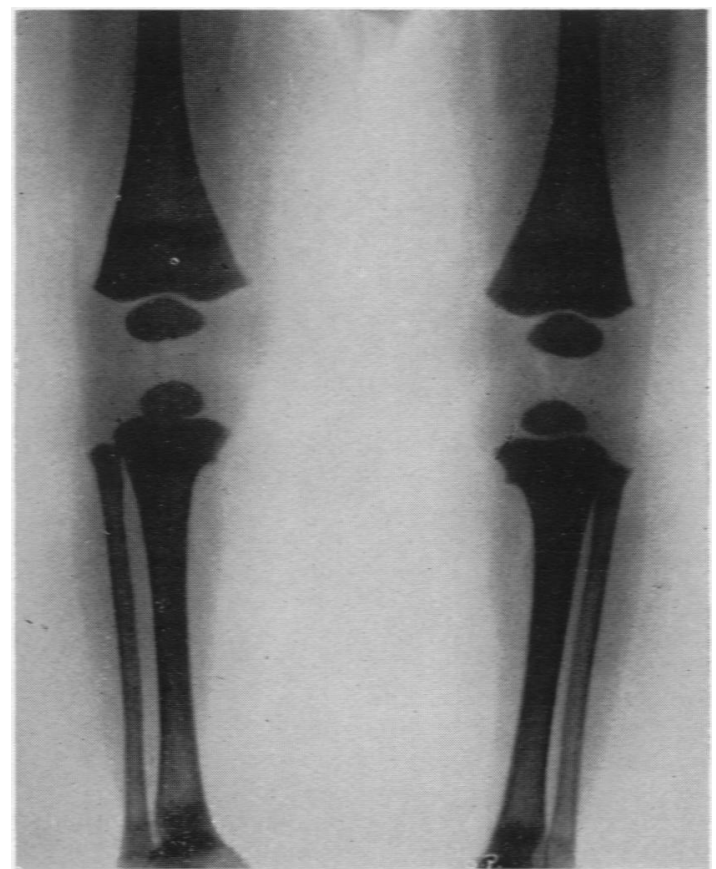

Fig. 2.-Double bands at the metaphyses on December 11,1947 . The original band is denser than the secondary band at the growing border. 
possible that lead was also being secreted in the mother's milk. Dufour Labastide, quoted by Gordon and Whitehead (1949), recorded several cases of poisoning in infants due to secretion of lead in the milk of mothers poisoned by skin cosmetics and hair dyes. In view of the high concentration of lead in the water supply it is surprising that the only sign of poisoning in the parents was a slight degree of hypochromic anaemia in the mother. This supports the opinion of McKhann and Vogt (1933) that children are more susceptible to severe intoxication than adults.

Symptomatology. The earliest symptoms in this case were listlessness and vomiting. According to McKhann and Vogt (1933) gastro-intestinal upset is commonly the first sign of lead poisoning in infants, but it appears that this upset may be minimal and insufficient to make the parents seek medical advice, so that in many cases, as in this one, the infant will present with full-blown signs of encephalopathy, a much commoner syndrome in the child than in the adult. Peripheral neuritis, which is the commoner form of involvement of the nervous system in the adult is rarely met with in the child.

The blood picture in this case did not show the punctate basophilia commonly seen in the red blood cells in chronic lead poisoning. As McKhann and Vogt (1933) point out, this is not a constant feature of the disease and is in any case not confined to lead poisoning. The moderate degree of hypochromic anaemia combined with a reticulocytosis seen in this case illustrate the other features of the usual blood picture in plumbism.

Radiological Findings. In retrospect the diagnosis of the present case appears fairly obvious. At the time of admission, however, the problem was by no means so simple, and the diagnosis might well have been missed but for the radiologist's report of the presence of dense bands at the anterior ends of the ribs and at the inferior angles of the scapulae noted in a skiagram of the chest taken to exclude pulmonary disease as a factor responsible for the convulsions. This finding led to systematic examination of the long bones with the result that similar bands were found at all the metaphyses, most marked at the lower ends of the radius, ulna, and femur and the upper end of the tibia. Dense bands at the metaphyseal borders were first reported in lead poisoning by Vogt (1930) and Park, Jackson, and Kajdi (1931), and are discussed at some length by Cooper (1947); they are present where bone growth is most active and are thought to be due to crowding together of the trabeculae and concentration of lead, which is deposited most readily in growing bone. Cooper states that similar zones of increased density in the metaphyses may also be produced by poisoning with bismuth and inorganic phosphorus, by congenital syphilis, and by a few other rare conditions, and may occasionally be met with in normal metaphyses. While the diagnosis of lead poisoning cannot be made from the radiological findings alone, he considers that ' in children metaphyseal densities in the most actively growing bones are the most consistent and reliable evidence available.' He reports a series of 19 cases due to inhalation of fumes from burning discarded battery cases; of this series only the two oldest, aged 17 and 20 years, and the two youngest, both aged 3 months, showed no radiological changes. According to Kasahara quoted by Cooper (1947) skeletal changes appear at the age of 5 to 6 months in breast fed Japanese infants poisoned by the excretion of lead in the milk of mothers who use lead-containing cosmetics extensively. The well-marked metaphyseal lines in the present case would appear, therefore, to have developed at an unusually early age.

The double zone of density seen in the present case (Fig. 2) is also mentioned by Cooper (1947) who suggests that it may be produced by further episodes of lead absorption or by a temporary increase of the amount of lead in the blood as a result of mobilization of lead previously deposited in the bones. Aub, Fairhall, Minot, and Reznikoff, (1925) have pointed out that, in general, the absorption, transport, deposition, and elimination of lead follows closely that of calcium and that factors influencing the metabolism of calcium also influence that of lead. Administration of calcium and vitamin $D$ promote the deposition of lead in the bones where it is inert and harmless, and consequently its removal from the blood and soft tissues. Conversely the administration of parathormone or a low calcium diet or the production of acidosis will result in the mobilization of lead from the bones into the blood stream whence some of it will be eliminated by the bowel and kidneys, and some will be deposited in the soft tissues. Lead so mobilized but not excreted will presumably in the course of time tend to be re-deposited in the growing bone ends.

It is interesting in the present case to follow the progress of the two lines at each metaphysis through a series of skiagrams taken at intervals of a few months. The original line, as might be expected, has been left behind in the shaft of the bone by the process of growth; the second line, first noted in December, 1947 (Fig. 2) remains at the metaphyseal border throughout a series of skiagrams taken in February, June (Fig. 3), and September, 1948. In December, 1947, the original line is the denser of the two but in the succeeding skiagrams the second 
or marginal line is considerably denser than the original one, which has, in fact, almost disappeared by September, 1948. The fact that the second line has remained at the metaphyseal border over a period of nine months proves that it cannot in this

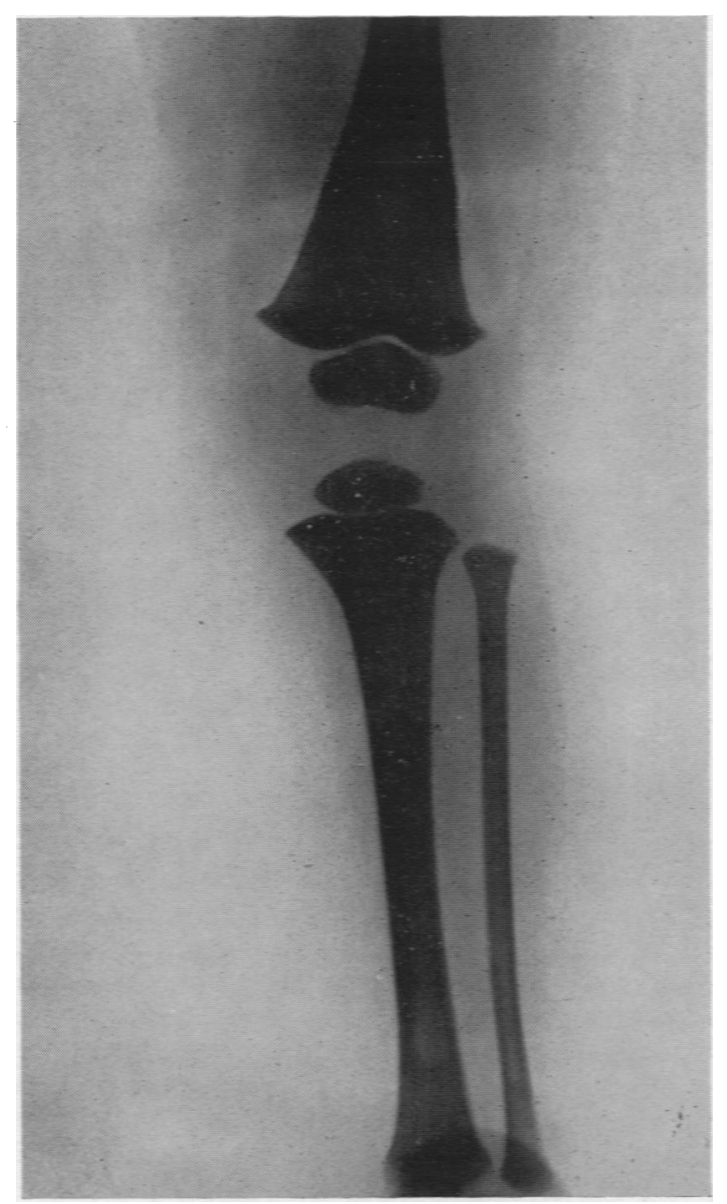

Frg. 3.-Double bands on June 7, 1948. The original band is now fading in the shaft of the bone and the secondary marginal band is the denser of the two.

case be the result of an isolated period of ingestion of lead or of mobilization of lead from the bones. The most likely explanation would seem to be that there is a continual slow mobilization of lead from the original depots after growth in that particular zone has ceased and a persistent tendency to deposition in growing bone.

Management and Prognosis. Theoretically it is desirable to eliminate the lead from the body as soon as possible for, while the lead in the bones is inert and harmless, it may at any time be mobilized as a result of acidosis with the result that, if the blood concentration rises sufficiently, fresh signs of poisoning will appear. In practice, however, it appears to be generally agreed that attempts to promote rapid elimination of lead by administration of parathormone or low calcium diet or acidproducing salts are fraught with considerable danger, particularly in children. It is difficult or impossible to control the rate at which lead is released into the bloodstream, and at any time the concentration of lead in the body fluids and nervous system may rise to a sufficiently high level to produce a fresh attack of encephalopathy with all its dangers, immediate and remote. It would seem safer to promote the deposition of lead in the bones by giving adequate amounts of vitamin $D$ and allow elimination to proceed slowly and gradually over a period of months or years, as it will, provided there is no further ingestion of lead.

The immediate treatment of established encephalopathy is unsatisfactory. Repeated lumbar puncture, the administration of magnesium sulphate by enema or intramuscular injection, and hypertonic glucose or saline solutions intravenously, have all been recommended for the reduction of the cerebral oedema but are of doubtful value. The convulsions are difficult to control by the usual sedatives, which in any case do not affect the underlying pathological process. As the symptoms of encephalopathy in the present case had subsided before the diagnosis was established, the question of treatment of the acute state did not arise.

The prognosis of lead poisoning in infancy is poor, and, where encephalopathy is present, the immediate mortality is high. Holt (cited by Ford, 1945) reported 13 deaths within a short time of admission among 20 children with convulsions due to lead encephalopathy. Of the seven survivors two were idiots and three more mildly mentally defective, one showed difficulty in gait, and only one was restored to normal health.

Byers and Lord (1943) surveyed a series of 20 children of school age who had been admitted to the Children's Hospital, Boston, some eight years previously with lead poisoning. Of these children only eight had shown any evidence of encephalopathy and none of these were really severe examples of the condition. All 20 were considered to have recovered completely when they were discharged from hospital, yet only one was making satisfactory progress at school at the time of re-examination, and the majority of them showed evidence of intellectual or emotional difficulties. The authors considered that all these children were mentally normal before their episodes of lead poisoning but 
from their paper it appears that in three cases aged 4 years or over at the time of the original admission the poisoning was the result of sucking lead paint. Whether a child of this age who sucks paint to the extent of developing lead poisoning can be considered mentally normal would appear to be a debatable point, but even if these three cases are discounted the after effects in the remainder are still discouraging.

The present patient is fortunate in having made a good recovery and shows no signs of permanent damage to the central nervous system, although the slight delay in speaking may be due to some mental retardation. His behaviour is otherwise perfectly normal, however, and it seems likely that any mental backwardness must be very slight.

\section{Summary}

The infrequency in the British literature of case records of lead poisoning in infancy is commented on.

A case of lead poisoning with encephalopathy in a young infant is described.

Although the lead was derived from the domestic water supply, the other members of the family showed no overt signs of poisoning.
The changes in the bones which, after radiological examination, first drew attention to the diagnosis are described.

I wish to thank Professor John Craig for advice and help in the preparation of this paper, Dr. W. H. Milligan for his advice and opinions on the radiological appearances, and Dr. John Smith of Aberdeen City Hospital laboratory for the water analysis.

\section{REFERENCES}

Aub, J. C., Fairhall, L. T., Minot, A. S., and Reznikoff, P. (1925). Medicine, 4, 1.

Byers, R. K., and Lord, E. E. (1943). Amer. J. Dis. Child., 66, 471.

Cooper, G. (1947). Amer. J. Roentgenol., 58, 129.

Findlay, L. (1935). Post-Grad. med. J., 11, 251.

Ford, F. R. (1945). 'Diseases of the Nervous System in Infancy, Childhood and Adolescence,' p. 664. Springfield, Ill.

Gordon, I., and Whitehead, T. P. (1949). Lancet, 2, 647.

Holt, L. E. (1940). 'Diseases of Infancy and Childhood,' p. 1368. New York.

McKhann, C. F., and Vogt, E. C. (1933). J. Amer. med. Ass., 101, 1131.

Park, E. A., Jackson, D., and Kajdi, L. (1931). Amer. J. Dis. Child., 41, 485.

Rodgers, T. S., Peck, J. R. S., and Jupe, M. H. (1934). Lancet, 2, 129.

Suckling, E. V. (1943). 'The Examination of Water and Water Supplies,' p. 107. London.

Vogt, E. C. (1930). Amer. J. Roentgenol., 24, 550. 